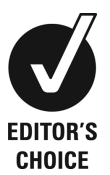

CHOICE
Department of Oral and Maxillofacial, Aintree University Hospital, Liverpool, UK

Correspondence to Dr Robert Gareth Michael Williams,

robwilliams@hotmail.co.uk

Accepted 1 February 2015

\title{
A case of craniofacial fibrous dysplasia associated with McCune-Albright syndrome lost to follow-up
}

\author{
Robert Gareth Michael Williams
}

\section{SUMMARY}

McCune-Albright syndrome is a rare fibro-osseous syndrome characterised by a classic triad of fibrous dysplasia (FD), café-au-lait macules and various underlying endocrinopathies. This case report describes how a patient was rediagnosed by a general dental practitioner following attendance for a routine dental examination. The patient had been previously diagnosed with the condition 28 years earlier but no follow-up or monitoring of her condition had taken place. As a result, she was found to have several undiagnosed and untreated complications of the disease including FD of the mandible, optic neuropathy and potential thyroid involvement.

\section{BACKGROUND}

This report discusses a rare but important fibro-osseous condition which carries with it significant comorbidities for the patient. Its estimated prevalence is between 1 in 100000 and 1 in 1000000 . The syndrome is caused by somatic activating mutations of the GNAS1 gene and is diagnosed by various imaging studies, genetic testing and endocrine evaluations. Ninety per cent of McCune-Albright syndrome (MAS) sufferers exhibit fibrous dysplasia (FD) in the craniofacial region. ${ }^{1}$ Despite being diagnosed with MAS at a young age, the patient appeared to have had no follow-up since and the condition had been missed by several healthcare professionals. It demonstrates how, despite taking a thorough medical history, things can be omitted and unusual signs or symptoms should always be investigated further.

\section{CASE PRESENTATION}

A 40-year-old Caucasian woman presented for a routine dental appointment with a general dental practitioner who was recently new to the practice. She reported having no relevant medical history, taking no medications and was fit and well.

A slight facial asymmetry was noted as soon as the patient entered the surgery due to a swelling at the lower left angle of the mandible (figure 1). On palpation, this appeared to be a bony hard expansion of the mandible, beginning at the left angle and extending anteriorly along the inferior and lateral borders. It measured approximately $4 \mathrm{~cm}$ in diameter and was apparently asymptomatic. On questioning, the patient stated she had been aware of the lump for a number of years.

A second observation was the presence of light brown pigmented patches on the lips and oral mucosa (figures 2-4). The patient reported that

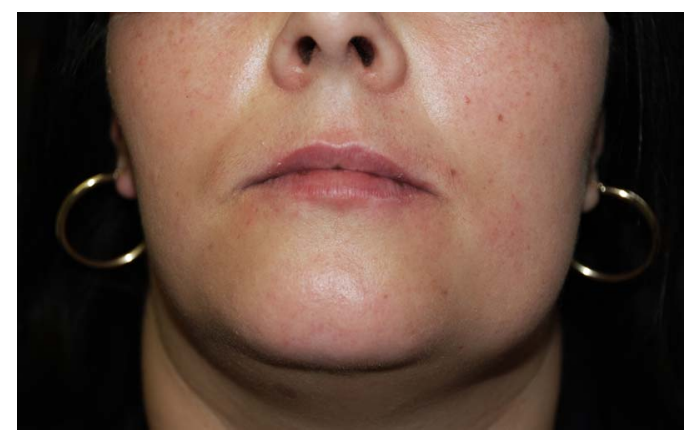

Figure 1 Asymmetry of the mandible due to a bony hard swelling at the left angle.

they had again been noted by a previous dentist who informed her that they were due to her ancestry and reassured her that no treatment was required. The patient also described having further light brown patches on her skin elsewhere, mainly on her left-hand side.

The final significant observations were that the patient had what appeared to be a thyroid goitre. (figure 5) and had lost her sight in the left eye. Inspection of the patient's notes revealed that the jaw mass and the pigmented patches had been observed by other dentists a number of years earlier, though no intervention was initiated. The spots had been interpreted as racial pigmentation and the swelling was not investigated further due to its asymptomatic nature. From the previous measurement of the swelling, it appeared to have grown slightly from 3 to $4 \mathrm{~cm}$ in diameter over the past 3 years.

The bony expansion of the jaw, light brown macules and potential thyroid goitre appeared to fit the classical triad of symptoms of MAS, and so a

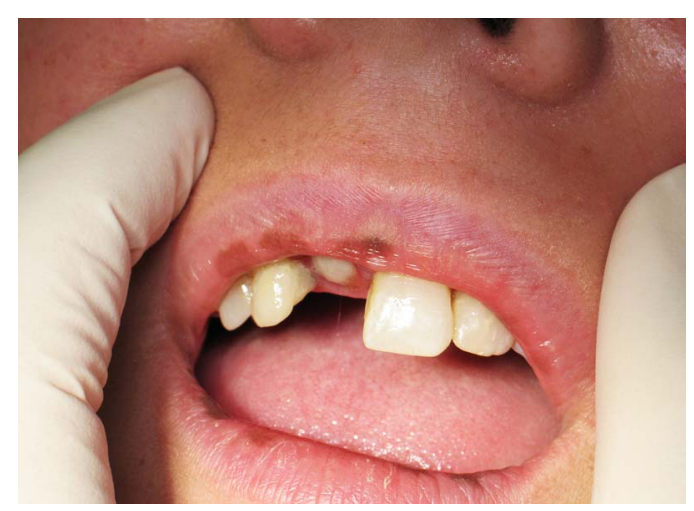

Figure 2 Café-au-lait macules on lips. 


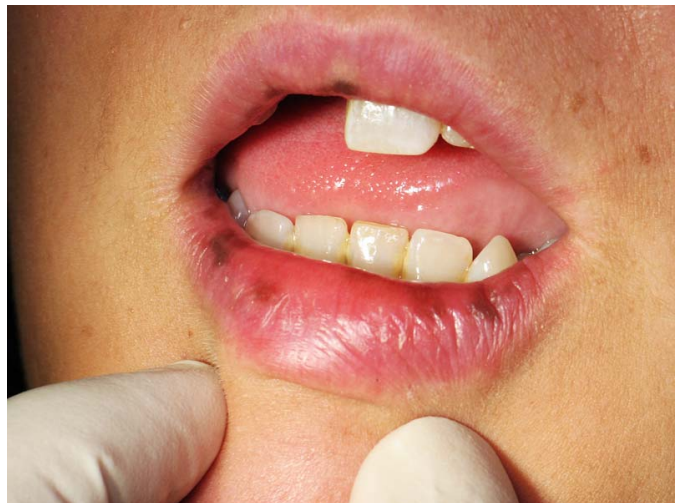

Figure 3 Perioral café-au-lait macules.

subsequent, more specific line of history taking was undertaken.

On discussion with the patient, it transpired that she had received a diagnosis of MAS as a teenager when she was admitted to hospital at age 12 with a left-sided hip fracture following a fall. This unusual fracture coupled with precocious puberty had led to further investigations and a diagnosis of MAS. The patient, however, maintained that she had never discussed it with, nor heard it mentioned by, any healthcare professionals since and had forgotten about it.

The further history taking also revealed that the patient suffered from unilateral left-sided chronic bony aches and stiffness from her hips, legs and back. She explained that visual disturbances in her left eye had begun at age 19 when she was told that a bony growth was pressing on her optic nerve which would eventually lead to her losing her vision. It was unclear as to exactly how this had been managed and what diagnosis had been made, though the patient explained that at the time she did not wish to receive any follow-up and no recalls or observations were organised.

Following this appointment, a referral was made to the local Oral and Maxillofacial Surgery (OMFS) unit at the Royal Victoria Infirmary in Newcastle where the patient was reviewed.

\section{INVESTIGATIONS}

Appropriate radiographs (orthopantomogram and posteroanterior mandible) were taken in the OMFS department, which demonstrates the asymmetry and FD affecting the lower left angle of the mandible. There is also increased radio-opacity within the left orbit (figures 6 and 7). A bone biopsy was

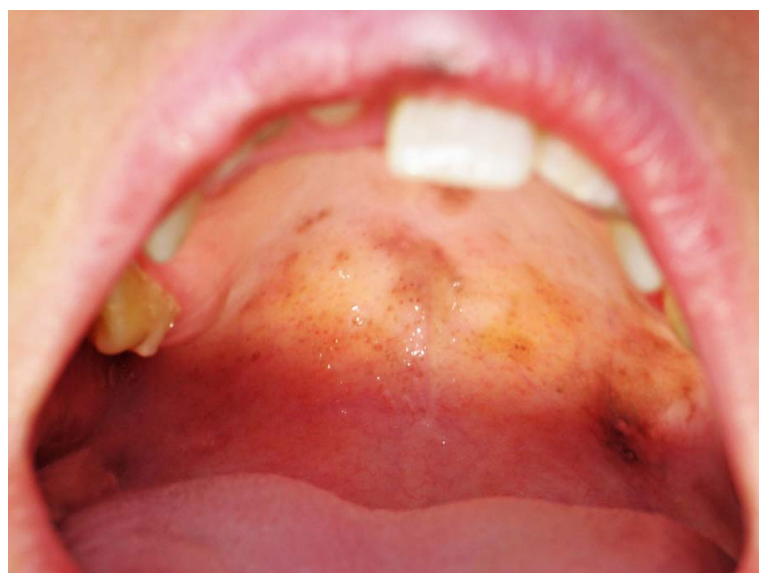

Figure 4 Café-au-lait macules on the palate.

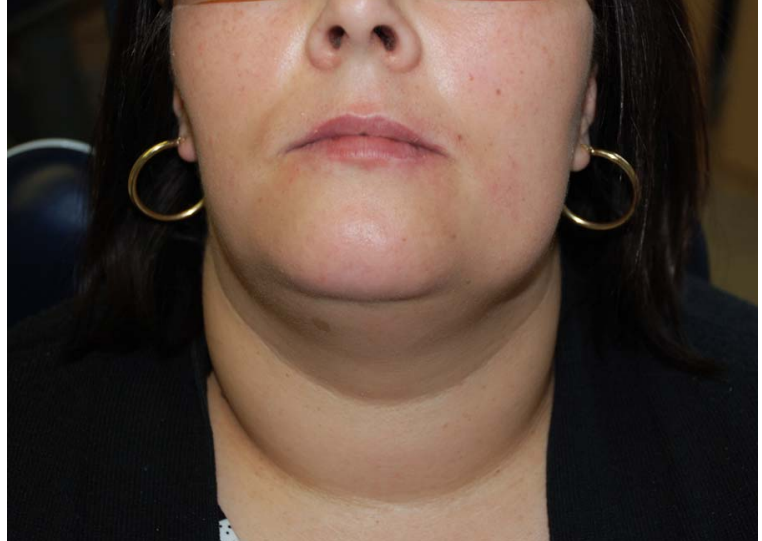

Figure 5 Neck goitre.

obtained from the site of expansion which confirmed the mass to be FD consistent with MAS.

\section{DIFFERENTIAL DIAGNOSIS}

McCune-Albright syndrome.

\section{TREATMENT}

Regular review and monitoring of the disease.

\section{OUTCOME AND FOLLOW-UP}

Given that the expansion was causing no symptoms, the patient decided at the OMFS review that she would prefer not to have any treatment for it. A decision was therefore made for the general dental practitioner to simply review the patient at regular intervals and monitor the expansion for any signs of growth or development of symptoms.

Since there was a strong suspicion that there may be other undiagnosed bone and endocrine problems related to the disease, a further referral was made for additional investigations with an endocrinologist and the patient is currently awaiting this appointment.

\section{DISCUSSION}

This patient appeared to have a textbook presentation of the disease, with a strong suggestion that she suffered from all of the classical symptoms. As is typical with most patients with MAS, an initial diagnosis was made during childhood. She initially presented with a fractured hip at age 12 , and it is well documented that pathological bone fractures at a young age can often be the presenting sign of the disease. ${ }^{2}{ }^{3}$

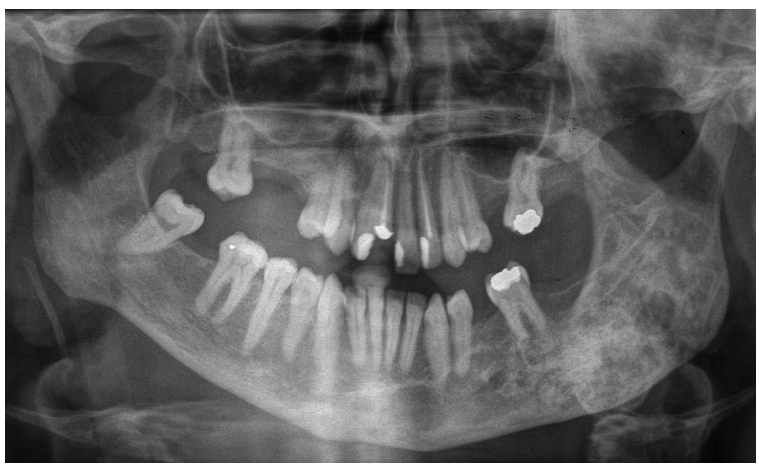

Figure 6 Orthopantomogram showing fibrous dysplasia at the left angle. 


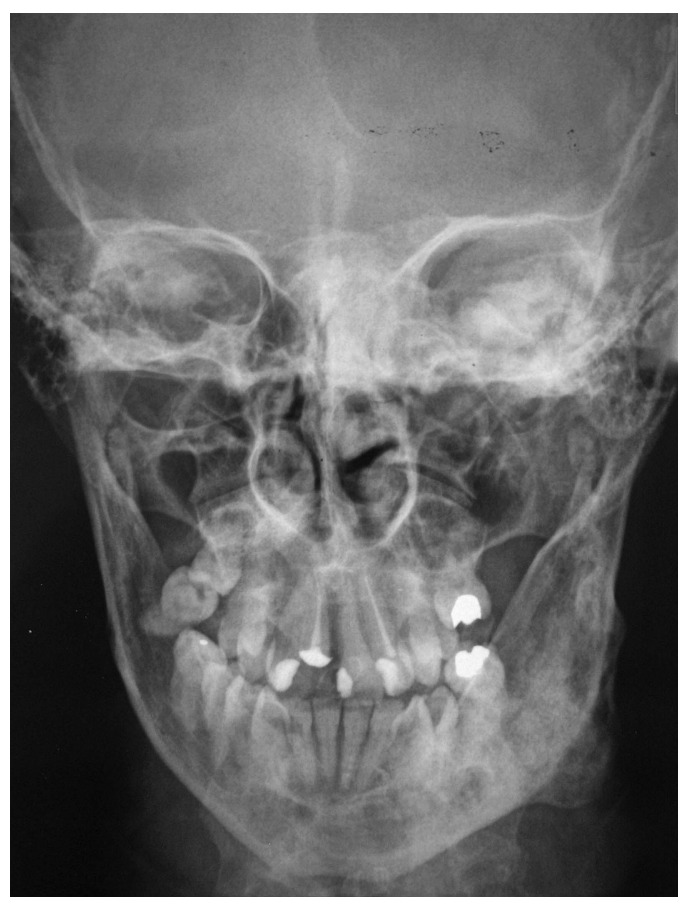

Figure 7 Posteroanterior view of the mandible showing fibrous dysplasia at the left angle.

Unfortunately, without access to the patient's medical records, it was impossible to know the exact reason for the patient being lost to follow-up subsequent to her initial diagnosis. It also remains unclear as to what diagnosis was made regarding her optic nerve compression which ultimately led to her unilateral loss of sight. The patient could not recall MAS being mentioned during the investigations, though without inspection of the clinical records one cannot be certain. Optic nerve compression leading to visual disturbances or loss of sight is a known complication of MAS, ${ }^{4-6}$ and it therefore stands to reason that the condition may be directly related to this patient's loss of sight, especially given the fact that the left eye was affected, which is in keeping with the unilateral nature of the disease.

On questioning, the patient reported a long-standing history of unilateral bone pains, particularly in her legs, hips and back, though she has never received a diagnosis for the cause. Bone pain is a recognised symptom of MAS, which appears to worsen with age and is often untreated. ${ }^{2} 7$

As previously mentioned, endocrine problems are a significant element of the disease; however, other than the precocious puberty, this patient had not been diagnosed with any other endocrinopathies. The physical appearance of the neck led to a suspicion of goitre, and hyperthyroidism is commonly associated with MAS, though the patient did not appear to exhibit any of the common symptoms of the condition. A recent review of the literature reported that much more often (in up to $68 \%$ of patients) the thyroid gland is involved without frank hyperthyroidism. This can manifest as an abnormal thyroid gland on ultrasound and deranged thyroid hormones. ${ }^{2}$ It should be noted that patients may go on to develop hyperthyroidism and should therefore be regularly monitored. ${ }^{2}$

Asymmetry and swelling are the most common symptoms when FD is found in the bones of the facial skeleton. ${ }^{8}$ Though the facial swelling and asymmetry on this patient was not a presenting complaint, it was something that, when questioned, she admitted to being very aware of but had not previously known its cause. Lesions of MAS-associated FD affecting the face can be described as quiescent, non-aggressive or aggressive, based on the speed of growth and the presence of other symptoms such as pain, pathological fracture or paraesthesia. ${ }^{8}$ The lesion in this case could be described as non-aggressive given the fact that it is asymptomatic and appears to be slow growing, though more comprehensive monitoring in the future will establish its exact rate of growth.

Guidelines have recently been published on the clinical management of craniofacial FD. ${ }^{8}$ They state that in patients with slow-growing or quiescent lesions that cause no symptoms or psychological distress, an annual review, at which sensory nerve testing, photographs and facial CT should be obtained, is likely to be adequate. More aggressive forms of the disease will often warrant surgical intervention. It is noteworthy that malignant transformation has been reported in less than 1\% of FD cases. ${ }^{2} 8$

It is well documented in the literature that FD can cause dental anomalies and is associated with increased prevalence of caries. Enamel hypoplasia, dentin dysplasia, taurodontic pulps, odontomas, tooth displacement and malocclusion have all been linked to the condition, and it is estimated that around $28 \%$ of patients with craniofacial FD will exhibit one or more of the aforementioned problems. This patient showed no signs of any dental abnormalities; she did have a high caries rate, though this was more likely to be related to dietary and oral hygiene factors as opposed to her MAS. ${ }^{1}$

\section{Learning points}

- McCune-Albright syndrome is rare (prevalence between 1 in 100000 and 1 in 1000000 ), but it is an important disease to be aware of due to its complexity and associated comorbidities.

- Patients do not always provide a complete or accurate medical history.

- A multidisciplinary approach is essential in managing such a complex disease effectively.

- It is important not to assume that just because previous colleagues have noted and dismissed lesions or signs, they do not warrant further investigation.

\section{Competing interests None.}

Patient consent Obtained.

Provenance and peer review Not commissioned; externally peer reviewed.

\section{REFERENCES}

1 Akintoye SO, Boyce AM, Collins MT. Dental perspectives in fibrous dysplasia and McCune-Albright syndrome. Oral Surg Oral Med Oral Pathol Oral Radiol 2013;116: e149-55.

2 Dumitrescu CE, Collins MT. McCune-Albright syndrome. Orphanet J Rare Dis 2008:3:12.

3 Kollerova J, Koller T, Zelinkova Z, et al. Treatment of pathological bone fractures in a patient with McCune-Albright syndrome. Case Rep Endocrinol 2013;2013:589872.

4 Boyce AM, Glover M, Kelly MH, et al. Optic neuropathy in McCune-Albright syndrome: effects of early diagnosis and treatment of growth hormone excess. J Clin Endocrinol Metab 2013;98:E126-34.

5 Yavuzer R, Khilnani R, Jackson IT, et al. A case of atypical McCune-Albright syndrome requiring optic nerve decompression. Ann Plast Surg 1999;43:430-5.

6 Sammut SJ, Kandasamy J, Newman W, et al. Relief of severe retro-orbital pain and vision improvement after optic-nerve decompression in polyostotic fibrous dysplasia: case report and review of the literature. Childs Nerv Syst 2008;24:515-20.

7 Kelly MH, Brillante B, Collins MT. Pain in fibrous dysplasia of bone: age-related changes and the anatomical distribution of skeletal lesions. Osteoporos Int 2008;19:57-63.

8 Lee JS, FitzGibbon EJ, Chen YR, et al. Clinical guidelines for the management of craniofacial fibrous dysplasia. Orphanet J Rare Dis 2012;7(Suppl 1):S2. 
Copyright 2015 BMJ Publishing Group. All rights reserved. For permission to reuse any of this content visit http://group.bmj.com/group/rights-licensing/permissions.

BMJ Case Report Fellows may re-use this article for personal use and teaching without any further permission.

Become a Fellow of BMJ Case Reports today and you can:

- Submit as many cases as you like

- Enjoy fast sympathetic peer review and rapid publication of accepted articles

- Access all the published articles

- Re-use any of the published material for personal use and teaching without further permission

For information on Institutional Fellowships contact consortiasales@bmjgroup.com

Visit casereports.bmj.com for more articles like this and to become a Fellow 